\title{
Trends in Neoadjuvant Approaches in Pancreatic Cancer
}

\author{
Lingling $\mathrm{Du}, \mathrm{MD}$, and Andrea Wang-Gillam, MD, PhD
}

\section{Abstract}

Pancreatic cancer (PDAC) is an aggressive tumor type associated with development of micrometastasis at an early stage. In attempt to eradicate disseminated disease, neoadjuvant therapy has been explored in patients with resectable and borderline resectable PDAC. In large retrospective studies, neoadjuvant therapy was associated with better survival compared with upfront surgery. Previously, trials more commonly used radiotherapy (RT) with small doses of chemotherapy as radiosensitizers. Recent studies, however, have incorporated full systemic doses of chemotherapy with or without RT before surgery with the hope of achieving adequate systemic chemotherapy coverage and improving survival. Several phase II trials have shown encouraging clinical benefits using the neoadjuvant approach. Large cooperative group studies are exploring the role of neoadjuvant treatment with newer combination chemotherapy regimens and modern RT techniques, which will provide more evidence regarding the utility of this approach.

J Natl Compr Canc Netw 2017;15(8):1070-1077 doi: 10.6004/jnccn.2017.0134

$\mathbf{P}_{\text {ancreatic cancer (PDAC) is the fourth leading cause }}$ of cancer-related mortality in the United States. ${ }^{1}$ Surgical resection provides the only chance of cure. Unfortunately, only approximately $10 \%$ to $20 \%$ of patients present with tumors amenable to resection. However, the 5 -year survival rate remains low at $10 \%$ to $20 \%$ in those who have undergone curative resection, ${ }^{2,3}$ with most patients experiencing distant recurrence. Therefore, clinical studies have examined additional treatment beyond resection with the hope of decreasing recurrence and improving survival. In the adjuvant setting, 5FU- or gemcitabine-based chemotherapy has improved outcomes. ${ }^{4-7}$ Still, fewer than one-third of patients with resected PDAC are cured. ${ }^{7}$ Researchers have explored the role of neoadjuvant therapy with the intent of improving complete resection (RO) rates and survival.

Traditionally, solid tumors are staged by tumor size $(\mathrm{T})$, nodal involvement $(\mathrm{N})$, and the presence of distant metastases (M). However, because most patients

From the Division of Medical Oncology, Department of Medicine, Washington University School of Medicine, St. Louis, Missouri. Submitted February 20, 2017; accepted for publication July 19, 2017. The authors have disclosed that they have no financial interests, arrangements, affiliations, or commercial interests with the with PDAC are not eligible for resection, clinical stage defined by radiographic imaging is more relevant to clinical practice. To better classify tumor resectability, an expert consensus group published their criteria on the resectability of PDAC in 2009. ${ }^{8}$ These criteria have been well recognized and modified by NCCN (Table 1). ${ }^{9}$ This article reviews the key trials of neoadjuvant therapy in resectable and borderline resectable (BR) PDAC.

\section{Neoadjuvant Therapy}

\section{Rationales of Neoadjuvant Approach}

Phase III trials have demonstrated a clear survival benefit with adjuvant chemotherapy. ${ }^{5,7}$ Multiple studies examined neoadjuvant therapy as an alternative to the traditional adjuvant approach. Neoadjuvant therapy offers patients the opportunity to receive full courses of treatment without potential delays from surgical compli- 
Neoadjuvant Therapy in Pancreatic Cancer

\begin{tabular}{|c|c|c|}
\hline & 2009 Expert Consensus & NCCN Guidelines \\
\hline \multicolumn{3}{|l|}{ Resectable } \\
\hline Arterial & Clear fat planes around the CA, HA, and SMA & No tumor contact with the CA, HA, SMA \\
\hline Venous & No tumor contact with SMV/PV & $\begin{array}{l}\text { No tumor contact with SMV/PV or } \leq 180^{\circ} \text { contact } \\
\text { without contour irregularity }\end{array}$ \\
\hline \multicolumn{3}{|c|}{ Borderline resectable } \\
\hline \multirow[t]{3}{*}{ Arterial } & Tumor abutment of SMA of $\leq 180^{\circ}$ & Tumor contact with SMA of $\leq 180^{\circ}$ \\
\hline & $\begin{array}{l}\text { Encasement of gastroduodenal artery up to the HA } \\
\text { without extension to the CA }\end{array}$ & $\begin{array}{l}\text { Tumor contact with HA without extension to the CA } \\
\text { or HA bifurcation }\end{array}$ \\
\hline & & Tumor contact with the CA of $\leq 180^{\circ}$ \\
\hline \multirow[t]{2}{*}{ Venous } & $\begin{array}{l}\text { Tumor contact with SMV/PV without encasement of the } \\
\text { nearby arteries, or short segment venous occlusion but } \\
\text { with suitable adjacent vessel allowing for safe resection } \\
\text { and reconstruction }\end{array}$ & $\begin{array}{l}\text { Tumor contact with SMV/PV of }>180^{\circ} \text {, contact of } \leq 180^{\circ} \\
\text { with contour irregularity or thrombosis of the vein } \\
\text { but with suitable adjacent vessel allowing for safe } \\
\text { resection and reconstruction }\end{array}$ \\
\hline & & Tumor contact with IVC \\
\hline
\end{tabular}

Abbreviations: CA, celiac axis; HA, hepatic artery; IVC, inferior vena cava; PV, portal vein; SMA, superior mesenteric artery; SMV, superior mesenteric vein.

cations. Systemic therapy early in the disease course (neoadjuvant) may have a better chance of depleting micrometastases, and it helps identify patients with aggressive tumor who are unlikely to benefit from surgery. Additionally, possible tumor shrinkage from neoadjuvant therapy may improve the R0 resection rate in patients with BR PDAC. To date, there have been no phase III trials demonstrating survival benefits from neoadjuvant treatment. However, a large retrospective study evaluated patients with clinical stage I or II resected pancreatic head adenocarcinoma from the National Cancer Database. ${ }^{10}$ Patients who received neoadjuvant therapy had significantly better survival compared with those who underwent upfront surgery (adjusted hazard ratio [HR], 0.83; 95\% CI, 0.73-0.89).

\section{Neoadjuvant Chemoradiotherapy}

The rationale of chemoradiotherapy (chemoRT) is to use chemotherapeutic agents as sensitizers to enhance the locoregional effect of radiotherapy (RT). A series of studies at the MD Anderson Cancer Center (MDACC) published in the 1990s demonstrated the feasibility of delivering RT with small doses of $5 \mathrm{FU}$ in the neoadjuvant setting. ${ }^{11,12}$ The phase II French FFCD 9704-SFRO trial used 5FU at $300 \mathrm{mg} /$ $\mathrm{m}^{2}$ on days 1 through 5 for 5 weeks and cisplatin at $20 \mathrm{mg} / \mathrm{m}^{2}$ on days 1 through 5 and 29 through 33 concurrent with RT of 50 Gy. ${ }^{13}$ Among 41 patients enrolled, 26 (63\%) underwent surgery, with an R0 rate of $81 \%$. The median overall survival (mOS) and 2-year survival rates were 9.4 months and 20\%, respectively, for all patients, and 11.7 months and $32 \%$, respectively, for resected patients.

In 1997, Burris et $\mathrm{al}^{14}$ demonstrated a clinical benefit with gemcitabine over 5FU in advanced PDAC, which led to the approval of gemcitabine in PDAC. After this result was published, studies have largely switched from 5FU- to gemcitabine-based regimens. A phase II trial at MDACC used gemcitabine at $400 \mathrm{mg} / \mathrm{m}^{2}$ weekly for 7 weeks with concurrent RT of $30 \mathrm{~Gy}$ in 86 patients with resectable or BR disease. ${ }^{15}$ More than half of patients needed a dose adjustment of gemcitabine, mostly due to hematologic toxicities; 64 patients $(74 \%)$ underwent resection, and the $\mathrm{R} 0$ rate was $89 \%$. The mOS and 5-year survival rate were 22.7 months and $27 \%$, respectively, for the entire cohort, and 34.0 months and $36 \%$, respectively, for the resected patients. In Europe, a German phase II study randomized patients with resectable or BR pancreatic head cancer to upfront surgery versus neoadjuvant chemoRT (gemcitabine, $300 \mathrm{mg} / \mathrm{m}^{2}$ and cisplatin, $30 \mathrm{mg} / \mathrm{m}^{2}$ on days $1,8,22$, and 29 with concurrent RT of 55.8 or 50.4 Gy) followed by surgery. ${ }^{16}$ Adjuvant gemcitabine was recommended after the CONKO-001 results were published. ${ }^{17} \mathrm{~A}$ total of 66 patients were eligible for data analysis. In the upfront surgery arm, 23 of 33 patients (70\%) underwent resection, with 16 (70\%) achieving an R0. In the neoadjuvant arm, 29 patients received chemoRT; 19 (58\%) underwent resection, with an $\mathrm{R} 0$ resection rate of $89 \%$. 
Du and Wang-Gillam

Neoadjuvant therapy did not increase the rates of high-grade postoperative complications. A total of 10 patients in the surgery arm and 7 in the neoadjuvant arm received adjuvant chemotherapy. The mOS for all and resected patients were numerically longer, favoring the neoadjuvant approach, but this was not statistically significant (surgery vs neoadjuvant: 14.4 vs 17.4 months for all patients; $P=.96$, and 18.9 vs 25.0 months for resected patients; $P=.79$ ). This study showed that preoperative chemoRT was safe and did not increase high-grade postoperative complications, but the sample size was too small to detect a survival advantage. In addition, the doses of gemcitabine and cisplatin used in the chemoRT regimen were too low for systemic control.

Because traditional chemoRT regimens have not yielded significant improvement in early-stage PDAC, several studies have added more chemotherapy courses. A phase II study at MDACC that enrolled 90 patients with resectable or BR disease used a chemotherapy regimen of gemcitabine, $750 \mathrm{mg} / \mathrm{m}^{2}$ and cisplatin, $30 \mathrm{mg} / \mathrm{m}^{2}$ biweekly for 4 doses followed by 4 weekly doses of gemcitabine, $400 \mathrm{mg} / \mathrm{m}^{2}$ with RT of 30 Gy. ${ }^{18}$ The full course of neoadjuvant treatment was completed in 79 patients; however, half of the patients needed hospitalization for toxicities. Resections were performed in 52 patients (58\%), with an $\mathrm{RO}$ rate of $96 \%$. The $\mathrm{mOS}$ were 17.4 and 31.0 months for all and resected patients, respectively. Compared with the other MDACC study that used the same chemoRT regimen but without additional chemotherapy, ${ }^{15}$ these results did not show any substantial improvement. One of the possible explanations is that the gemcitabine and cisplatin doublet was not an effective regimen for PDAC. Additionally, a 4-week course was considered to be short for systemic control.

Another phase II study used full-dose gemcitabine on days 1,8 , and 15 and oxaliplatin, $85 \mathrm{mg} /$ $\mathrm{m}^{2}$ on days 1 and 15 every 4 weeks for 2 cycles, with RT of 30 Gy delivered with cycle $1 .{ }^{19}$ A total of 68 patients were treated, including 23 resectable, $39 \mathrm{BR}$, and 6 unresectable. One-fourth of patients required hospitalization during the preoperative treatment. One patient had a sudden death, and a second died of progressive cancer and infection after cycle 1 . Forty-three patients $(63 \%)$ underwent resection, with an $\mathrm{RO}$ rate of $84 \%$. The $\mathrm{mOS}$ were 18.2 and 27.1 months for all and resected patients, respectively.
Those who had resectable disease had an mOS of 26.5 months, whereas those with BR disease had an mOS of 18.4 months. Notably, adjuvant chemotherapy was completed in 24 patients, suggesting that neoadjuvant treatment may not jeopardize the delivery of adjuvant chemotherapy. However, the toxicities with this neoadjuvant approach were still of concern, and the outcome was not particularly impressive. Another phase II study randomized patients with resectable PDAC to upfront surgery versus neoadjuvant therapy with a 3-week course of full-dose gemcitabine for 2 cycles followed by gemcitabine $50 \mathrm{mg} / \mathrm{m}^{2}$ twice weekly with RT of $54 \mathrm{~Gy}^{20} ; 20$ patients were randomized to the surgery arm and 18 to the neoadjuvant arm. More patients in the surgery arm underwent resection ( $75 \%$ vs $61 \%$ ), but more patients in the neoadjuvant arm had an RO resection $(64 \%$ vs $33 \%)$. The mOS were 19.5 months with upfront surgery and 27.5 months with neoadjuvant treatment $(P=.973)$. Thus far, results from these neoadjuvant chemoRT studies have not been overtly promising, likely because the benefit of a neoadjuvant approach relies heavily on the efficacy of the regimen used, and the lack of effective systemic therapy has been a main challenge in the neoadjuvant setting.

In the meantime, recent studies have shown that both FOLFIRINOX and nab-paclitaxel plus gemcitabine improved survival in patients with advanced PDAC. ${ }^{21,22}$ These regimens were noted to have greater toxicities than single-agent gemcitabine, but the survival advantage warrants further investigation in patients with early-stage disease. For example, the ongoing Alliance A021101 study is examining the role of neoadjuvant modified FOLFIRINOX (mFOLFIRINOX) followed by capecitabine-based chemoRT in patients with BR PDAC (ClinicalTrials.gov identifier: NCT01821612). Patients are treated with 4 cycles of mFOLFIRINOX followed by RT of 50.4 Gy with capecitabine at $825 \mathrm{mg} / \mathrm{m}^{2}$ twice daily. A pilot study confirmed the feasibility of this regimen. ${ }^{23}$ Among the 22 patients who received treatment, $64 \%$ had $\geq$ grade 3 toxicities. Despite that, 15 patients $(68 \%)$ underwent surgical resection, with an $\mathrm{R} 0$ rate of $93 \%$. The mOS was 21.7 months for all patients. These results were encouraging given that the survival of patients with BR PDAC was usually between 12 and 15 months. ${ }^{24}$ 
In summary, neoadjuvant chemoRT was tested in multiple phase II studies with various outcomes (Table 2). Researchers are still exploring the best neoadjuvant chemoRT approach. Incorporating fulldose chemotherapy into RT provides favorable antitumor efficacy but is associated with significant toxicities. Using standard RT with concurrent low-dose chemotherapy but with the addition of modern systemic chemotherapy regimens is being explored in both the United States and Europe (Table 3). In addition, recent advancements in RT techniques have made stereotactic body RT (SBRT) or hypofractionated RT available. These techniques may offer more accurate delivery, shorter treatment duration, and less toxicity. The ongoing Alliance A021501 study is examining the role of neoadjuvant mFOLFIRINOX with or without hypofractionated RT. The hope is that the results of these studies will offer a better insight into the role and best strategy of neoadjuvant chemoRT.

\section{Neoadjuvant Chemotherapy}

PDAC has a high propensity for early development of metastasis. The role of RT in PDAC remains controversial even in the adjuvant setting and for locally advanced disease. ${ }^{25}$ More researchers have applied systemic chemotherapy alone in the neoadjuvant setting with the intent of maximizing the delivery of chemotherapy to eradicate occult metastases. So far, most of the data are from small phase II studies using a gemcitabine-based regimen. In Europe, British investigators randomized 50 patients with resectable PDAC to receive either gemcitabine, $1,000 \mathrm{mg} / \mathrm{m}^{2}$ weekly for 43 days or the combination of gemcitabine $\left(1,000 \mathrm{mg} / \mathrm{m}^{2}\right)$ and cisplatin $(25$ $\mathrm{mg} / \mathrm{m}^{2}$ ) weekly for 43 days omitting day $22 .{ }^{26}$ The combination regimen was later modified to omit days 15 and 36 due to the high-grade hematologic toxicities experienced by patients. Gemcitabine alone was generally well tolerated. In the combination group, half of the patients experienced grade $3 / 4$ toxici-

\section{Table 2. Clinical Trials of Neoadjuvant CRT}

\begin{tabular}{|c|c|c|c|c|c|c|c|c|c|c|}
\hline Author & Year & $\mathbf{N}$ & $\begin{array}{l}\text { Clinical } \\
\text { Stage }\end{array}$ & Treatment & Chemotherapy & CRT & $\begin{array}{l}\text { Resection } \\
\text { Rate } \\
(\%)\end{array}$ & $\begin{array}{l}\text { R0 Rate } \\
\text { (\%) }\end{array}$ & $\begin{array}{c}\text { Median } \\
\text { Survival } \\
(\mathrm{mo}) \\
\text { All/RSCT }\end{array}$ & $\begin{array}{c}\text { Survival } \\
\text { Rate } \\
(\%) \\
\text { All/RSCT }\end{array}$ \\
\hline $\begin{array}{l}\text { Le Scodan } \\
\text { et } \mathrm{al}^{13}\end{array}$ & 2008 & 41 & $\begin{array}{l}\text { Considered R } \\
\text { by surgeons }\end{array}$ & CRT & & $\begin{array}{l}5 \mathrm{FU}, 300 \mathrm{mg} / \mathrm{m}^{2} \\
5 \mathrm{~d} / \mathrm{wk} \times 5 \mathrm{wk} \\
\text { cis, } 20 \mathrm{mg} / \mathrm{m}^{2} \\
\text { days } 1-5,29-33 \\
+\mathrm{RT}, 50 \mathrm{~Gy}\end{array}$ & 63 & 81 & $9.4 / 11.7$ & $\begin{array}{c}20 / 32 \\
(2 y)\end{array}$ \\
\hline Evans et $\mathrm{al}^{15}$ & 2008 & 86 & $\mathrm{R}$ or $\mathrm{BR}$ & CRT & & $\begin{array}{l}\text { Gem, } 400 \mathrm{mg} / \mathrm{m}^{2} \\
\text { weekly x } 7+\mathrm{RT} \\
30 \mathrm{~Gy}\end{array}$ & 74 & 89 & $23 / 34$ & $\begin{array}{c}27 / 36 \\
(5 \mathrm{y})\end{array}$ \\
\hline \multirow[t]{2}{*}{ Golcher et al ${ }^{16}$} & 2015 & 66 & $\mathrm{R}$ or $\mathrm{BR}$ & A: Surgery & & & 70 & 70 & $14.4 / 18.9$ & \\
\hline & & & & $\begin{array}{l}\mathrm{B}: \mathrm{CRT}+ \\
\text { surgery }\end{array}$ & & $\begin{array}{l}\text { Gem, } 300 \mathrm{mg} / \mathrm{m}^{2} \\
\text { and cis, } 30 \mathrm{mg} / \\
\mathrm{m}^{2} \text { days } 1,8,22, \\
29+\mathrm{RT}, 55.8 \text { or } \\
50.4 \mathrm{~Gy}\end{array}$ & 58 & 89 & $17.4 / 25.0$ & \\
\hline $\begin{array}{l}\text { Varadhachary } \\
\text { et al }{ }^{18}\end{array}$ & 2008 & 90 & $\mathrm{R}$ or $\mathrm{BR}$ & $\begin{array}{l}\text { Chemo then } \\
\text { CRT }\end{array}$ & $\begin{array}{l}\text { Gem, } 750 \mathrm{mg} / \mathrm{m}^{2} \\
\text { and cis, } 30 \mathrm{mg} / \mathrm{m}^{2} \\
\text { biweekly x } 4\end{array}$ & $\begin{array}{l}\text { Gem, } 400 \mathrm{mg} / \mathrm{m}^{2} \\
\text { weekly x } 4 \text { + RT, } \\
30 \mathrm{~Gy}\end{array}$ & 58 & 96 & $17.4 / 31.0$ & \\
\hline Kim et al ${ }^{19}$ & 2013 & 68 & $\begin{array}{l}\mathrm{R}, \mathrm{BR} \text {, } \\
\text { unresectable }\end{array}$ & $\begin{array}{l}\text { CRT + } \\
\text { chemo }\end{array}$ & $\begin{array}{l}\text { Gem, } 1 \mathrm{~g} / \mathrm{m}^{2} \text { days } \\
1,8,15 \text { and oxa, } \\
85 \mathrm{mg} / \mathrm{m}^{2} \text { days } 1, \\
15 \text { every } 28 \mathrm{~d}\end{array}$ & $\begin{array}{l}\text { Gem, } 1 \mathrm{~g} / \mathrm{m}^{2} \text { day } \\
1,8,15 \text { and oxa, } \\
85 \mathrm{mg} / \mathrm{m}^{2} \text { days } 1 \text {, } \\
15 \text { every } 28 \mathrm{~d}+ \\
\text { RT, } 30 \mathrm{~Gy}\end{array}$ & 63 & 84 & $18.2 / 27.1$ & \\
\hline \multirow[t]{2}{*}{ Casadei et $\mathrm{al}^{20}$} & 2015 & 38 & $\mathrm{R}$ & A: surgery & & & 75 & 33 & $19.5 /-$ & \\
\hline & & & & $\begin{array}{l}\text { B: chemo } \\
+ \text { CRT + } \\
\text { surgery }\end{array}$ & $\begin{array}{l}\text { Gem, } 1 \mathrm{~g} / \mathrm{m}^{2} \text { days } \\
1,8 \text { every } 21 \mathrm{~d} \times 2\end{array}$ & $\begin{array}{l}\text { Gem, } 50 \mathrm{mg} / \mathrm{m}^{2} \\
\text { twice weekly + } \\
\text { RT, } 54 \text { Gy }\end{array}$ & 61 & 64 & 27.5/- & \\
\hline Katz et $\mathrm{al}^{23}$ & 2016 & 22 & BR & $\begin{array}{l}\text { Chemo } \\
+ \text { CRT + } \\
\text { surgery }\end{array}$ & mFOLFIRINOX x 4 & $\begin{array}{l}\text { Cape, } 825 \mathrm{mg} / \mathrm{m}^{2} \\
\mathrm{bid}+\mathrm{RT}, 50.4 \mathrm{~Gy}\end{array}$ & 68 & 93 & 21.7/- & $\begin{array}{l}-/ 67 \\
(1.5 y)\end{array}$ \\
\hline
\end{tabular}

Abbreviations: BR, borderline resectable; cape, capecitabine; chemo, chemotherapy; cis, cisplatin; CRT, chemoradiotherapy; gem, gemcitabine; mFOLFIRINOX, modified FOLFIRINOX; oxa, oxaliplatin; R, resectable; RSCT, resected; RT, radiotherapy. 
Du and Wang-Gillam

\begin{tabular}{|c|c|c|c|c|c|c|c|c|}
\hline Author & Year & $\mathrm{N}$ & Clinical Stage & Chemotherapy & $\begin{array}{c}\text { Resection Rate } \\
(\%)\end{array}$ & $\begin{array}{c}\text { Complete } \\
\text { Resection Rate } \\
(\%)\end{array}$ & $\begin{array}{c}\text { Median } \\
\text { Survival } \\
(\mathrm{mo}) \\
\text { All/RSCT }\end{array}$ & $\begin{array}{c}\text { Survival } \\
\text { Rate } \\
(\%) \\
\text { All/RSCT }\end{array}$ \\
\hline \multirow[t]{2}{*}{ Palmer et $\mathrm{al}^{26}$} & \multirow[t]{2}{*}{2007} & \multirow[t]{2}{*}{50} & $R$ & $\begin{array}{l}\text { A: Gem, } 1 \mathrm{~g} / \mathrm{m}^{2} \\
\text { weekly } x 6\end{array}$ & 38 & 78 & 9.9/- & $\begin{array}{l}42 /- \\
(1 \mathrm{y})\end{array}$ \\
\hline & & & & $\begin{array}{l}\text { B: Gem, } 1 \mathrm{~g} / \mathrm{m}^{2}, \text { cis, } 25 \\
\mathrm{mg} / \mathrm{m}^{2} \text { on days } 1,8, \\
15,29,36,43 a\end{array}$ & 70 & 78 & $15.6 /-$ & $\begin{array}{l}62 /- \\
(1 \mathrm{y})\end{array}$ \\
\hline Heinrich et $a^{27}$ & 2008 & 28 & $\mathrm{R}$ and $\mathrm{BR}$ & $\begin{array}{l}\text { Gem, } 1 \mathrm{~g} / \mathrm{m}^{2}, \text { cis, } 50 \\
\mathrm{mg} / \mathrm{m}^{2} \text { biweekly x } 4\end{array}$ & 86 & & -126.5 & \\
\hline Motoi et $\mathrm{al}^{29}$ & 2013 & 35 & $\mathrm{R}$ and $\mathrm{BR}$ & $\begin{array}{l}\text { Gem, } 1 \mathrm{~g} / \mathrm{m}^{2} \text { days } 1,8, \\
\mathrm{~S}-1,40 \mathrm{mg} / \mathrm{m}^{2} \times 14 \mathrm{~d} \\
\text { every } 21 \mathrm{~d} \times 2\end{array}$ & 86 & 87 & $19.7 / 34.7$ & $\begin{array}{l}46 / 56 \\
(2 \mathrm{y})\end{array}$ \\
\hline $\mathrm{O}^{\prime}$ Reilly et al ${ }^{28}$ & 2014 & 38 & $\mathrm{R}$ & $\begin{array}{l}\text { Gem, } 1 \mathrm{~g} / \mathrm{m}^{2} \text {, oxa, } 80 \\
\mathrm{mg} / \mathrm{m}^{2} \text { biweekly x } 4\end{array}$ & 71 & 74 & $27.2 /-$ & $\begin{array}{l}63 /- \\
(1.5 y)\end{array}$ \\
\hline
\end{tabular}

Abbreviations: BR, borderline resectable; cis, cisplatin; gem, gemcitabine; oxa, oxaliplatin; R, resectable; RSCT, resected.

${ }^{a}$ This regimen was later changed to gem, $1 \mathrm{~g} / \mathrm{m}^{2}$ and $\mathrm{cis}, 25 \mathrm{mg} / \mathrm{m}^{2}$ on days $1,8,22,29,43$ due to toxicities associated with the original schedule.

ties. Compared with single-agent gemcitabine, the combination group demonstrated a better resection rate (70\% vs 38\%) and mOS (15.6 vs 9.9 months). One-year survival rate was $42 \%$ in the gemcitabine arm versus $62 \%$ in the combination arm. Another Swiss study used 4 biweekly doses of gemcitabine, $1,000 \mathrm{mg} / \mathrm{m}^{2}$ and cisplatin, $50 \mathrm{mg} / \mathrm{m}^{2} .^{27}$ A total of 28 patients were recruited, and 24 underwent resection. Neoadjuvant chemotherapy did not increase the postoperative morbidity or mortality. The mOS was 26.5 months for resected patients.

As these European studies demonstrated the feasibility of neoadjuvant chemotherapy in PDAC, researchers in the United States also started to explore the role of this approach. A phase II trial enrolled 38 patients with resectable disease. ${ }^{28}$ Patients received 4 biweekly doses of gemcitabine, $1,000 \mathrm{mg} / \mathrm{m}^{2}$ and oxaliplatin, $80 \mathrm{mg} / \mathrm{m}^{2}$. Preoperative chemotherapy was mostly well tolerated, but there were 3 grade 5 adverse events, including 2 cardiac events and 1 cerebrovascular accident. Twenty-seven patients (71\%) underwent resection, with an $\mathrm{R} 0$ rate of $74 \%$. The mOS and 18-month survival rate were 27.2 months and $63 \%$, respectively, for all patients. Notably, 26 of 27 patients received adjuvant gemcitabine. The median age of patients was also older, at 73 years. These results again emphasize that neoadjuvant chemotherapy may not compromise the delivery of adjuvant treatment, even in an older population.

Apart from the gemcitabine/platinum regimen, a Japanese phase II study tested the combination of gemcitabine and S-1 (gemcitabine, $1,000 \mathrm{mg} / \mathrm{m}^{2}$ on days 1 and 8 and S-1, $40 \mathrm{mg} / \mathrm{m}^{2}$ orally twice daily for 14 days every 21 days for 2 cycles) in the neoadjuvant setting for resectable and BR PDAC. ${ }^{29}$ A total of 35 patients received treatment, 19 of whom had clearly resectable disease. Neutropenia, leukopenia, and rash were the most common grade $3 / 4$ adverse events. Thirty patients $(86 \%)$ underwent surgical resection, with an $\mathrm{R} 0$ rate of $87 \%$. Adjuvant gemcitabine was given in 24 patients. The mOS and actuarial 2-year survival rates were 19.7 months and $46 \%$, respectively, for the entire cohort, and 34.7 months and 56\%, respectively, for resected patients. The survival of patients who underwent resection was impressive, partially owing to the benefit of S-1 in the Japanese population, which was also proven by the superior survival in the phase III study of adjuvant $\mathrm{S}-1$ in PDAC. ${ }^{30}$

In conclusion, small phase II trials demonstrated the feasibility of neoadjuvant chemotherapy (Table 4). Some studies have shown favorable outcomes, but data are still limited. Newer combinations, such as FOLFIRINOX and gemcitabine plus nab-paclitax$\mathrm{el}$, are being tested as the neoadjuvant regimens in large cooperative group trials (Table 3 ). The ongoing SWOG 1505 study is comparing mFOLFIRINOX versus gemcitabine plus nab-paclitaxel as 2 neoadjuvant regimens in patients with resectable PDAC (ClinicalTrials.gov identifier: NCT02562716). On the other hand, 2 German trials are comparing the neoadjuvant approach with adjuvant chemotherapy: the NEPAFOX study is comparing perioperative FOLFIRINOX with adjuvant gemcitabine in patients with resectable or BR PDAC (NCT02172976), 
Neoadjuvant Therapy in Pancreatic Cancer

\begin{tabular}{|c|c|c|c|c|c|}
\hline Trial & Phase & Stage & Neoadjuvant Treatment & $\begin{array}{l}\text { Adjuvant } \\
\text { Treatment }\end{array}$ & $\begin{array}{l}\text { ClinicalTrials.gov } \\
\text { Identifier }\end{array}$ \\
\hline \multirow[t]{2}{*}{ Alliance A021501 } & \multirow[t]{2}{*}{ II } & \multirow[t]{2}{*}{ BR } & A: mFOLFIRINOX $\times 8$ cycles & \multirow[t]{2}{*}{ FOLFOX $\times 4$ cycles } & \multirow[t]{2}{*}{ NCT02839343 } \\
\hline & & & B: mFOLFIRINOX $\times 7$ cycles + 5-day RT & & \\
\hline Alliance A021101 & II & BR & $\begin{array}{l}\text { mFOLFIRINOX } \times 4 \text { cycles }+ \text { CRT with } \\
\text { RT } 50.4 \text { Gy and cape, } 825 \mathrm{mg} / \mathrm{m}^{2} \text { bid }\end{array}$ & Gem $\times 2$ cycles & NCT01821612 \\
\hline \multirow[t]{2}{*}{$\begin{array}{l}\text { PANDAS- } \\
\text { PRODIGE44 }\end{array}$} & \multirow[t]{2}{*}{ II } & \multirow[t]{2}{*}{ BR } & $\begin{array}{l}\text { A: mFOLFIRINOX + CRT with } 50.4 \text { Gy and } \\
\text { cape }\end{array}$ & \multirow[t]{2}{*}{$\begin{array}{l}\text { Gem or modified } \\
\text { 5FU/LV }\end{array}$} & \multirow[t]{2}{*}{ NCT02676349 } \\
\hline & & & B: mFOLFIRINOX & & \\
\hline \multirow[t]{2}{*}{ SWOG 1505} & \multirow[t]{2}{*}{ II } & \multirow[t]{2}{*}{$\mathrm{R}$} & A: mFOLFIRINOX & \multirow[t]{2}{*}{ Gem $\times 3$ cycles } & \multirow[t]{2}{*}{ NCT02562716 } \\
\hline & & & B: Nab-paclitaxel/gem & & \\
\hline \multirow[t]{2}{*}{ NEPAFOX } & \multirow[t]{2}{*}{$\| / I I I$} & \multirow[t]{2}{*}{$\mathrm{R}$ or $\mathrm{BR}$} & A: No treatment & A: Gem $\times 6$ cycles & \multirow[t]{2}{*}{ NCT02172976 } \\
\hline & & & B: FOLFIRINOX $\times 6$ cycles & $\begin{array}{l}\text { B: FOLFIRINOX } \times 6 \\
\text { cycles }\end{array}$ & \\
\hline \multirow[t]{2}{*}{ NEONAX } & \multirow[t]{2}{*}{ II } & \multirow[t]{2}{*}{$\mathrm{R}$} & A: Nab-paclitaxel/gem $\times 2$ cycles & $\begin{array}{l}\text { A: Nab-paclitaxel/ } \\
\text { gem } \times 4 \text { cycles }\end{array}$ & \multirow[t]{2}{*}{ NCT02047513 } \\
\hline & & & B. No treatment & $\begin{array}{l}\text { B: Nab-paclitaxel/ } \\
\text { gem } \times 6 \text { cycles }\end{array}$ & \\
\hline
\end{tabular}

Abbreviations: BR, borderline resectable; cape, capecitabine; CRT, chemoradiotherapy; gem, gemcitabine; 5FU/LV, 5-fluorouracil/leucovorin; mFOLFIRINOX, modified FOLFIRINOX; R, resectable; RT, radiotherapy.

whereas the NEONAX study is examining the role of nab-paclitaxel and gemcitabine given in different strategies to patients with resectable disease (NCT02047513). Patients are randomized to receive either 2 cycles before and 4 cycles after surgery versus 6 cycles postoperatively. It will be interesting to see the results of these 2 German studies, because neoadjuvant therapy may also come at a price. Patients who experience too much toxicity from neoadjuvant treatment may lose their opportunity for surgery and have a worse outcome. The hope is that results of these studies will answer some critical questions, including the role of neoadjuvant chemotherapy and the optimal preoperative regimens.

\section{Challenges With the Interpretation of Clinical Studies}

Interpreting the currently available study results remains challenging. Small sample size and heterogeneous patient populations often render direct comparison across trials difficult. This heterogeneity may stem from the definitions of resectability, the changes of these definitions over time, subjective interpretations of vascular involvement, and whether adjuvant chemotherapy was applied. In older trials, the definitions of resectable PDAC were usually nebulous. Having PDAC "considered to be resectable by attending surgeons" was the major inclusion criterion for trials conducted before 2000.11,13 In contrast, more recent studies adapted a clearer definition of resectability, usually in accordance with the NCCN Clinical Practice Guidelines in Oncology (NCCN Guidelines). ${ }^{19,28}$ However, even the definition of resectability itself has undergone multiple changes as surgical techniques advance. For instance, a tumor with no contact with major arteries but with $\leq 180$ degree contact with superior mesenteric vein/portal vein $(\mathrm{SMV} / \mathrm{PV})$ without contour irregularity would fall into the category of BR in the 2009 Expert Consensus, ${ }^{8}$ whereas the same tumor would be considered resectable in the latest NCCN Guidelines. ${ }^{9}$ Similarly, tumors with $\leq 180$ degree contact with the celiac axis were unresectable according to the 2009 Expert Consensus but are BR in the latest NCCN Guidelines. ${ }^{9}$ In addition, many old studies enrolled different patient populations with a mixture of resectable, BR, and locally advanced disease, with results only reported on the entire study cohort. Advancements in staging techniques and central read of baseline imaging have also improved patient selection in more recent studies. Furthermore, adjuvant chemotherapy with gemcitabine became the standard of care only after the results of CONKO-001 study were published in 2007, ${ }^{17}$ and hence was not offered in studies conducted before that. Moreover, after the ESPAC-4 study showed a survival benefit with adjuvant gem- 
Du and Wang-Gillam

citabine plus capecitabine over gemcitabine alone, ${ }^{7}$ ongoing neoadjuvant trials may need to incorporate this combination as one of the adjuvant regimens, necessitating stratification and careful analysis when interpreting future results.

An important question remains regarding the role of RT in addition to neoadjuvant chemotherapy. So far, there have been no large randomized studies comparing neoadjuvant chemotherapy with neoadjuvant chemoRT head-to-head. The ongoing French PANDAS-PRODIGE44 study is comparing mFOLFIRINOX plus capecitabine-based chemoRT versus mFOLFIRINOX alone (ClinicalTrials.gov identifier: NCT02676349). Another cooperative group study, Alliance A021501, is randomizing patients with BR PDAC to preoperative treatment with either 8 cycles of mFOLFIRINOX or 7 cycles of mFOLFIRINOX plus a 5-day RT course (NCT02839343). The hope is that the results of these studies will clarify the role of neoadjuvant RT.

\section{Conclusions}

PDAC is known to be a systemic disease with development of micrometastases even at an early stage. Retrospective studies suggest that neoadjuvant therapy followed by resection offered better survival compared with upfront surgery. Early clinical trials more often emphasized the delivery of RT and used small doses of chemotherapy as radiosensitizers, whereas recent studies have shifted toward systemic doses of chemotherapy with or without RT. Several phase II trials have shown encouraging survival outcome, but a series of fundamental questions remain, including the role of RT in addition to chemotherapy, the optimal chemotherapy regimens, and the timing and duration of perioperative treatment. With recent advances in chemotherapeutic drugs and RT techniques, large cooperative group studies are examining these modern treatments to specifically address these questions. To shed light on the role of RT, the Alliance A021501 and the French PRODIGE 44 studies are comparing neoadjuvant mFOLFIRNOX with and without RT. To answer the question of the best neoadjuvant chemotherapy regimen, the SWOG S1505 trial is comparing FOLFIRINOX with gemcitabine and nab-paclitaxel head-to-head. Regarding the timing and sequence of perioperative therapy, the German NEPAFOX and NEONAX trials are trying to compare perioperative versus adjuvant chemotherapy (Table 4). The hope is that results of these studies will provide better insight into the role of and best neoadjuvant approach for PDAC.

\section{References}

1. Siegel RL, Miller KD, Jemal A. Cancer statistics, 2016. CA Cancer J Clin 2016;66:7-30.

2. Trede M, Schwall G, Saeger HD. Survival after pancreatoduodenectomy. 118 consecutive resections without an operative mortality. Ann Surg 1990;211:447-458.

3. Nitecki SS, Sarr MG, Colby TV, et al. Long-term survival after resection for ductal adenocarcinoma of the pancreas. Is it really improving? Ann Surg 1995;221:59-66.

4. Neoptolemos JP, Stocken DD, Friess H, et al. A randomized trial of chemoradiotherapy and chemotherapy after resection of pancreatic cancer. N Engl J Med 2004;350:1200-1210.

5. Oettle H, Neuhaus P, Hochhaus A, et al. Adjuvant chemotherapy with gemcitabine and long-term outcomes among patients with resected pancreatic cancer: the CONKO-001 randomized trial. JAMA 2013;310:1473-1481.

6. Neoptolemos JP, Stocken DD, Bassi C, et al. Adjuvant chemotherapy with fluorouracil plus folinic acid vs gemcitabine following pancreatic cancer resection: a randomized controlled trial. JAMA 2010;304:1073-1081.

7. Neoptolemos JP, Palmer DH, Ghaneh P, et al. Comparison of adjuvant gemcitabine and capecitabine with gemcitabine monotherapy in patients with resected pancreatic cancer (ESPAC-4): a multicentre, open-label, randomised, phase 3 trial. Lancet 2017;389:1011-1024

8. Callery MP, Chang KJ, Fishman EK, et al. Pretreatment assessment of resectable and borderline resectable pancreatic cancer: expert consensus statement. Ann Surg Oncol 2009;16:1727-1733.

9. Tempero MA, Malafa MP, Al-Hawary M, et al. NCCN Clinical Practice Guidelines in Oncology: Pancreatic Adenocarcinoma, Version 2.2017. Accessed July 12, 2017. To view the most recent version of these guidelines, visit NCCN.org.

10. Mokdad AA, Minter RM, Zhu H, et al. Neoadjuvant therapy followed by resection versus upfront resection for resectable pancreatic cancer: a propensity score matched analysis. J Clin Oncol 2017;35:515-522.

11. Evans DB, Rich TA, Byrd DR, et al. Preoperative chemoradiation and pancreaticoduodenectomy for adenocarcinoma of the pancreas. Arch Surg 1992;127:1335-1339.

12. Pisters PW, Abbruzzese JL, Janjan NA, et al. Rapid-fractionation preoperative chemoradiation, pancreaticoduodenectomy, and intraoperative radiation therapy for resectable pancreatic adenocarcinoma. J Clin Oncol 1998;16:3843-3850.

13. Le Scodan R, Mornex F, Partensky C, et al. Histopathological response to preoperative chemoradiation for resectable pancreatic adenocarcinoma: the French Phase II FFCD 9704-SFRO trial. Am J Clin Oncol 2008; $31: 545-552$

14. Burris HA III, Moore MJ, Andersen J, et al. Improvements in survival and clinical benefit with gemcitabine as first-line therapy for patients with advanced pancreas cancer: a randomized trial. J Clin Oncol 1997;15:24032413.

15. Evans DB, Varadhachary GR, Crane CH, et al. Preoperative gemcitabinebased chemoradiation for patients with resectable adenocarcinoma of the pancreatic head. J Clin Oncol 2008;26:3496-3502.

16. Golcher $\mathrm{H}$, Brunner TB, Witzigmann $\mathrm{H}$, et al. Neoadjuvant chemoradiation therapy with gemcitabine/cisplatin and surgery versus immediate surgery in resectable pancreatic cancer: results of the first prospective randomized phase II trial. Strahlenther Onkol 2015;191:7-16.

17. Oettle H, Post $S$, Neuhaus P, et al. Adjuvant chemotherapy with gemcitabine vs observation in patients undergoing curative-intent resection of pancreatic cancer: a randomized controlled trial. JAMA 2007;297:267-277. 
18. Varadhachary GR, Wolff RA, Crane $\mathrm{CH}$, et al. Preoperative gemcitabine and cisplatin followed by gemcitabine-based chemoradiation for resectable adenocarcinoma of the pancreatic head. J Clin Oncol 2008;26:3487-3495.

19. Kim EJ, Ben-Josef E, Herman JM, et al. A multi-institutional phase 2 study of neoadjuvant gemcitabine and oxaliplatin with radiation therapy in patients with pancreatic cancer. Cancer 2013;119:2692-2700.

20. Casadei R, Di Marco M, Ricci C, et al. Neoadjuvant chemoradiotherapy and surgery versus surgery alone in resectable pancreatic cancer: a singlecenter prospective, randomized, controlled trial which failed to achieve accrual targets. J Gastrointest Surg 2015;19:1802-1812.

21. Conroy $T$, Desseigne $F$, Ychou $M$, et al. FOLFIRINOX versus gemcitabine for metastatic pancreatic cancer. N Engl J Med 2011;364:1817-1825.

22. Von Hoff DD, Ervin T, Arena FP, et al. Increased survival in pancreatic cancer with nab-paclitaxel plus gemcitabine. N Engl J Med 2013;369:16911703

23. Katz MH, Shi $\mathrm{Q}$, Ahmad SA, et al. Preoperative modified FOLFIRINOX treatment followed by capecitabine-based chemoradiation for borderline resectable pancreatic cancer: Alliance for Clinical Trials in Oncology Trial A021101. JAMA Surg 2016;151:e161137.

24. Yamada S, Fujii T, Sugimoto $H$, et al. Aggressive surgery for borderline resectable pancreatic cancer: evaluation of National Comprehensive Cancer Network Guidelines. Pancreas 2013;42:1004-1010.
25. Hammel P, Huguet F, van Laethem JL, et al. Effect of chemoradiotherapy vs chemotherapy on survival in patients with locally advanced pancreatic cancer controlled after 4 months of gemcitabine with or without erlotinib: the LAP07 randomized clinical trial. JAMA 2016;315:1844-1853.

26. Palmer DH, Stocken DD, Hewitt $\mathrm{H}$, et al. A randomized phase 2 trial of neoadjuvant chemotherapy in resectable pancreatic cancer: gemcitabine alone versus gemcitabine combined with cisplatin. Ann Surg Oncol 2007;14:2088-2096.

27. Heinrich S, Pestalozzi BC, Schafer M, et al. Prospective phase II trial of neoadjuvant chemotherapy with gemcitabine and cisplatin for resectable adenocarcinoma of the pancreatic head. J Clin Oncol 2008;26:2526-2531.

28. O'Reilly EM, Perelshteyn A, Jarnagin WR, et al. A single-arm, nonrandomized phase II trial of neoadjuvant gemcitabine and oxaliplatin in patients with resectable pancreas adenocarcinoma. Ann Surg 2014;260:142-148

29. Motoi F, Ishida K, Fujishima F, et al. Neoadjuvant chemotherapy with gemcitabine and S-1 for resectable and borderline pancreatic ductal adenocarcinoma: results from a prospective multi-institutional phase 2 trial. Ann Surg Oncol 2013;20:3794-3801.

30. Uesaka K, Boku N, Fukutomi A, et al. Adjuvant chemotherapy of S-1 versus gemcitabine for resected pancreatic cancer: a phase 3, open-label, randomised, non-inferiority trial (JASPAC 01). Lancet 2016;388:248-257.

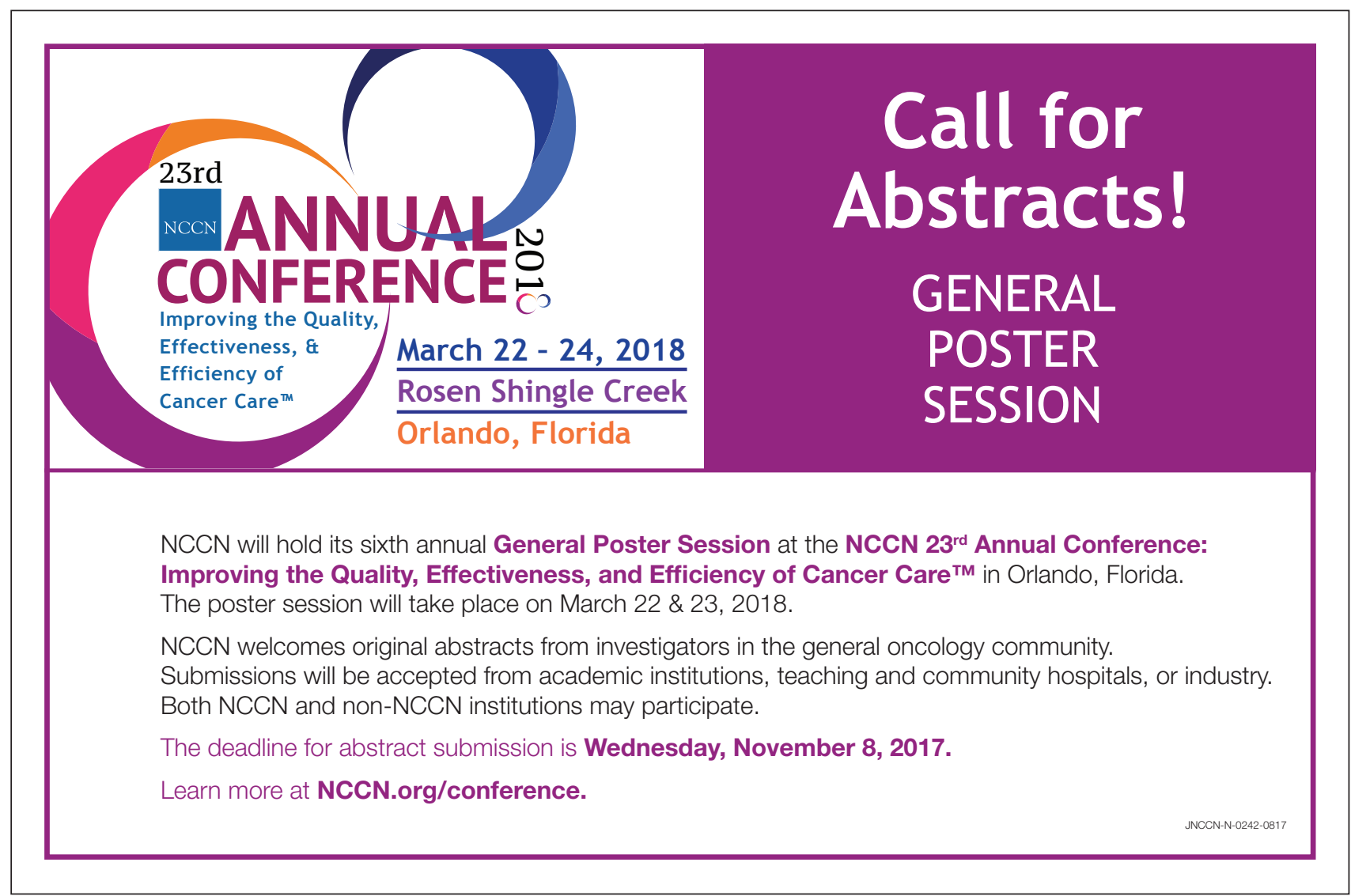

